\title{
SOCIO-ECONOMIC CONVERGENCE IN MODELS OF ENDOGENOUS ECONOMIC GROWTH
}

\author{
Włodzimierz Szkutnik ${ }^{1, a}$ and Weronika Szkutnik ${ }^{2, b}$ \\ ${ }^{1}$ Department of Statistical and Mathematical Methods in Economics, Katowice, 1 Maja 50 street, 40- \\ 287, Poland \\ ${ }^{2}$ UBS AG, Zurich, Switzerland \\ aszkutnik@ue.katowice.pl, bweronika.szkutnik@gmail.com \\ "Corresponding author
}

Cite as: Szkutnik W., Szkutnik W. (2018). Socio-economic convergence in models of endogeneous economic growth. Ekonomicko-manazerske spektrum, 12(2), 1-14.

Available at: dx.doi.org/10.26552/ems.2018.2.1-14

\begin{abstract}
The main results regarding determined goals of the paper concern the analysis of convergence in relation to the convergence processes from the point of view of physical capital and human knowledge, as well as labour resources. They usually refer to Mankiw's model that is a generalisation of the neoclassical Solow model. The major goal of deliberations conducted in the paper can lead to the conclusion that the phenomenon of convergence raises several methodological controversies resulting from inclusion of the very method of GDP per capita estimation, or firstly, the additional Mankiw's variable, i.e. human capital. Various sources, frequently different in the assessment of specific economic indicators prove, that in the countries of significant underdevelopment, the share of human capital followed what was not always positive in other regions of the world. The paper indicates the emergence of knowledge capital that is an empirically weakly defined variable, yet vital in convergence analyses. The measurements of knowledge capital applied in various models are usually not the same or reliable, which causes poor identification of the model, and the lack of possibility to compare obtained results. This leads to a distortion of the model of evaluation of the level of cohesion in compared economies. It results from the fact that such resources as human capital are not directly observable. The paper presents other possible ways of measuring the knowledge capital proposed in the literature, and it especially indicates that it requires the adoption of additional restrictive assumptions. In particular, it is assumed that the pace of technological progress is constant over time and between countries. The paper also evaluates the chances of convergence of countries with a lower degree of economic and social development, while taking into account the economic context.
\end{abstract}

Keywords: global flows, convergence, endogenous model

JEL Classification: F02, F22

\section{Introduction}

The paper initiates the discussion on the issues of economic cohesion of countries or world regions in conditions of various concepts of convergence and the ways in which it is defined.

The main goal of the paper is to refer the deliberations to previously functioning attitude concerning regulations that aim at equalizing the level and quality of life of various groups of European countries. Presentation of the way in which the difficult problem of human capital measurement that is highly significant in the evaluation of endogenous models is 
circumvented is also vital. More broadly discussed method resulting from research de la Fuente (2003) is explained against the background of studies conducted for EU and confirmed by results of surveys restricted in the paper because of broad character of the issues of theoretical resolutions applied in his studies for the assessment of the method of evaluation of human capital in convergence models.

\subsection{Classification of Convergences}

In synthetic approach, the notion of economic convergence with reference to the countries and regions can be interpreted in two ways: 1) as convergence of sigma type $(\sigma)$ when diversity in the level of incomes per capita is increasing (e.g. GDP per capita); 2) as divergence of beta type $(\beta)$, when economic systems of lower level of development show higher pace of growth in comparison with more developed economic systems, i.e. when there is an inverse relationship between the initial level of income (GDP per capita) and the growth rate. In this case, conditional and absolute convergences are distinguished.

It is a fact that less developed countries can show higher growth rate, which does not guarantee that diversification of income will decline. Barro \& Sala-i-Martin (1990) It is stated Friedman (2011) that $\beta$ convergence is a necessary but not sufficient determinant to achieve $\sigma$ convergence. Absolute convergence (unconditional) of $\beta$ type occurs when poor countries or regions develop faster than wealthy countries independently of the initial conditions and the level of development, whereas conditional convergence is observed when processes of cohesion, or convergence in other words, concern a group of countries or regions that are relatively homogenous (of similar income or structural parameters). Such a classification is closely related to economic growth with additional factors taken into consideration. They perform a control function in constructed models. In this aspect, absolute convergence is associated with the occurrence of the so-called catch-up effect - through faster economic development, poorer countries catch up with the countries that are initially wealthier. When the phenomenon of beta-convergence is observed, sigma-convergence can also occur. It takes place when income disparities between countries or regions are declining over time. (Barro \& Sala-and-Martin, 1990) We can also distinguish $\gamma$ convergence. It is another type of convergence that is less frequently analysed in the literature and refers to the change of place in the ranking of prosperity of countries or regions. (Wędrowska, 2013)

Generally, quantitative identification of $\beta$ convergence triggers some problems of numerical nature. This aspect of the analysis of the phenomenon of cohesion will be more comprehensibly discussed in further part of the paper. There is a problem of choosing the right method for estimating the constructed model when there are implicit dependencies between the control variables leading to the creation of large estimation errors. The problems arising from proper measurement of human capital factor will also be emphasised in further part. Such classification is closely correlated with economic growth that without doubt results from research and development of countries on the one hand, and on the other is a result of external supply from wealthy countries which they provide not only because of moral and humanitarian reasons (Gariepy, 2018) or for the purpose of equalization of differences between these countries and also entire world continents.

\subsection{Processes of Economic Convergence in the Light of the Growth Theory}

In the past and currently developing growth theory, two groups of models are distinguished, i.e. neoclassical, represented by R.M. Solow's model (1956) as well as its further modifications consisting mainly in extending the notion of capital into physical and 
human capital, and endogenous models that emerged and were developing in 1980s and 1990s as a result of critical analysis of neoclassical models. (Romer, 1986)

In the latest discussions concerning convergence, econometricians' position is noticed. Within economic growth, they identified numerous variables of control character that individually or collectively affect the growth, which implies the fact that convergence disparity has a significant impact on real economic growth. The list of these variables includes investment rate, level of education or education, trade-to-GDP ratio, financial deepening and public consumption. They are most generally applied indicators from the list. It is only stated here that in a formal (model) dimension, estimated coefficient of initial income regression model usually becomes negative and statistically significant if only any combination of these variables on the right side of the equation of growth regression is considered. (Barro \& Sala-iMartin, 1995). The assumption that is typical of convergence that there is a relatively high level of investment, education, trade and other components even only indirectly affecting growth is highly significant in this interpretation.

\subsection{Negation of Recognised Characteristics of Convergence}

At multitude of meanings of the phenomenon of convergence, economic convergence that is the area of our interest is explained by the aspiration of less developed economies to reduce the gaps in the estimation of development measured mainly by GDP per capita level, that are also distant from the group of developed countries in terms of development in other areas of existence. It is not possible to achieve such a model without considerable raw material resources, intellectually high level of social development but also synergy of various, often untypical processes not related to economy. Exceptions do not exist, and many examples can be shown. (Klein, 2007) In this case complete negation of process convergence is appropriate. Such an attitude, also shared in this paper, can raise some methodological controversies, but finds confirmation in many studies and observations regarding currently observed processes.

However, complete existence of the basis for the phenomena broadly supporting cohesion processes on the level of countries and regions (convergence) cannot be denied. BalDomanska (2013) Yet, possible convergence between economies in the meaning defined by types of convergences described above do not always have logical justification resulting from applied models. There are many reasons for this situation and the supporters of these opinions find convincing explanations. Rodrik (2011) This attitude is definite but allows to present the severity of operation of various mechanisms related to economies. While stimulating processes that reactivate occurrence of the mechanisms of this law, large economic organisms act only out of particular reasons. It must be clearly emphasised, which is stated by other researchers, that diminishing income per capita results from unnecessarily stimulated overemployment, which brings the wave of low incomes, while not causing decrease in corporate income. Globalisation, which in a meaning is an accelerator of convergence processes, in this context does not stand the test of positive example if social organisms compete only due to existential reasons. (Rifkin, 2000, Van Ewijk \& Ekins, 2018)

An interesting, empirically verified, yet too little exposed hypothesis that reduction of differences between economies of EU countries is accompanied by strengthening or enhancement of disparities on the level of regions is noticed here. In addition, the increase in per capita income reacts to increase in the income inequality index to some extreme level assessed as an average. This was already articulated several decades earlier in the $20^{\text {th }}$ century. (Friedmann, 2011, Halkos \& Tsionas, 2001)

Now, will be presented by Piketty (2014) a rather controversial opinion of ideological ostracism towards current trends relating to economic diversification between countries. 
(Reisman, 2015) The way in which society, economy and the inequalities accompanying them are perceived, are noticed here. Innovatively conducted analysis of empirical data, with a deep substantive presentation of significant problems "waiting" for social determinants in the 21st century, significantly determines new concepts in economics. Piketty is the first economist to be successful while comprehensively proving his following statement: "Those who have, will be given". Attacked world plutocracy can not stand the test of criticism in the light of his statements. According to many reviews published in the most widely read American magazines, Piketty's "Capital in the 21st Century" is written just to demolish the great economic pedestals (sails) of our time. They write that Piketty's work is economic history that has not been assessed on such a scale. It is obvious, that this is an evaluation that revolutionizes the way in which people have been thinking about economic history over the last two centuries. What is important from the point of view of the issues of economic convergence discussed in this paper, especially in the context of poverty, is the explicitness of statements concerning data from 200 years regarding the distribution of wealth and income in the prosperous world. It is this mass of data that allows Piketty to show, that in the language of the laws of large numbers, you cannot ignore the evidence and arguments contained in it.

\section{Methodology - New Growth Theory in the Symbolism of Endogenous Models}

The formal basis for economic growth models has been evolving throughout the nineteenth century until the present day Samuelson \& Nordhaus (2010). In the development of formalized thought - in science describing the real world in symbolism of models, the translation of economic conditions led to models of economic growth. Generally, the convention of division of models outlines the dichotomy of growth into endogenous and neoclassical models classified as the new theory of growth. They form the basis for the convergence methodology, that is focused on in our considerations.

Neoclassical growth models by Solow, Ramsey \& Diamond (1956), coming from the 1950s, and later from the 20th century, deriving from the classical construction that applies the main indicators of economic growth, create a class of contemporary models that try to justify unexpectedly occurring economic effects not predicted by previously constructed formal models.

\subsection{Endogenous vs Neoclassical Models. Measurement of Convergence}

The basic endogenous models include Romer's learning-by-doing model, the Lucas's model, Rebelo's model (1986), models with an increasing number of goods, and models with improving quality of goods. The new growth theory also includes the modification of the Solow model, i.e. the Mankiwa-Romer-Weil model (1992), which is its extension, but already included in the new theory of growth, because it introduces a new factor, i.e. human capital.

Neoclassical models with neoclassical production function are the basis for deriving the law of diminishing returns. It is important that they explain what has still been functioning, not only in Africa or other regions that are entering the technological and IT development phase but are still underdeveloped, but also explains the economic behaviours of such "giants" as the USA or other Western countries. This is because so far, a power like the United States uses quite prosaic methods of influence on other countries, that are often contrary to the principles of free trade. (Paltan et al., 2018)

On the other hand, in endogenous models there are at least constant incomes from reproducible production factors. What is more important, is the fact that in endogenous 
models - in contrast to neoclassical ones - determinants of long-term economic growth are well explained. (Tokarski, 2007) However, this increase in individual models of this group depends on many different factors. In the endogenous model describing the cohesion of regions, control variables including the investment rate, as the share of investments in the gross domestic product in the $i$-th region in the $t$ period, real investment outlays per 1 employed aged over 15 in $i$-th region and in $t$ year can be considered. Data on gross $y_{i t}$ value are the basis for determining $\sigma$ convergence, which for a group of regions or countries is determined by standard deviations of natural logarithms according to the formula

$$
\sigma_{t}=\sqrt{\frac{\sum_{i=1}^{N}\left(\ln y_{i t}-\ln \overline{y_{t}}\right)^{2}}{N}}
$$

where $\quad \mathrm{N}$ is the number of tested convergence agglomerate subjects.

Logarithms are a consequence of the construction of the Solow model having an exponential form Tokarski (2007), which is logarithmic for importing variables into a linear form. It is more clearly explained in further part.

Of course, the $\sigma$ convergence process is noticeable in such an agglomerate if the value of standard deviation $\sigma_{t}$ decreases from period to period.

This property of the studied agglomerate of regions or countries is, as previously emphasized, a prerequisite for the occurrence of $\beta$ type convergence.

As has already been stated, absolute and conditional convergence is distinguished in relation to beta type convergence. In absolute convergence, the measurement of the economic growth rate of an $i$ object in the final $T$ period is referred to the initial value of the $y_{i 0}$ product (capital, income) for particular $i$ objects of the whole agglomerate of economies $(i=1, \ldots, N)$.

This is expressed by the hypothesis of unconditional convergence deriving from the Solow-Swan model Dowrick \& Rogers (2002), from which various empirical variants explaining its meaning were implied. While examining absolute convergence, actually the influence of the initial $Y_{i 0}$ capital of an $i$ country from a certain group of countries $(i=$ $0,1, \ldots, N)$ on its value in the $T$ period, which falls on one employee is considered. Capital to work ratio, i.e. basically per capita income towards labor resources considered in the original model, is marked by $k_{1}$ and $k_{2}$, which corresponds to a poorer and richer country. Other growth determinants guarantee access to the same technology, the same population growth rate $(n)$ and the saving tendency $(s)$. With these assumptions, all countries are expected to converge to the same $k^{*}$ ratio (capital to work) in a determined state, production per capita and per capita consumption what marked as $\left(k^{*}, y^{*}, c^{*}\right)$, assuming the same rate of population growth $(n)$. It results from the stability of the Solow-Swan model which predicts that both poor and rich countries will approach the same $k^{*}$.

In other words, in the corrective categories, as $k_{1}<k_{2}$ the marginal product of capital in relation to labour is higher in poor countries than in rich countries, therefore poor people will accumulate more capital and increase their property status relatively more intensively. (Dowrick \& Rogers, 2002), Solow, 1980) Such model simplification can easily be subject to absolute criticism, but proponents of the neoclassical theory perceive this scheme as relevant and reasonably explaining such situation.

In contemporary thought of economic growth in the aspect of beta conditional convergence, other additional factors (control variables) are considered. They primarily include: capital $K$, labour $L$ and human resources in science and technology $H_{\text {it }}$ or $H R S T_{i t}$, measured in a variety of ways, including the number of graduates of faculties included in the "science and technology" category or employed in the professions desired in terms of their education in the $i$ country (region) in the $t$ year. Due to its specific character, this variable is 
more oriented towards potential rather than authentic human resources of the country (region). Still another type of variable marked by TETR is the share of professionally active population with higher education in the total number of professionally active people with higher education in a given age range in the total number of economically active population in the $i$ region (country) and in the $t$ period.

In the further part of the paper, divergent methods of measuring control variables and discrepancies in their determination will also be mentioned. They certainly do not facilitate the assessment of the model and what affects the interpretation of results. Special attention is focussed on it in the work. (de la Fuente \& Domenech, 2000)

\subsection{Endogenous Models in Convergence}

As is shown by their very name, endogenous models explain economic growth in the way resulting from changes in the factors occurring in the model. This feature constitutes the opposite of the neoclassical theory of growth, where long-term growth depended on the exogenous technological progress introduced into the model along with other assumptions. Islam (1995), Islam (2003), Jabłonski (2011) Achieving endogenous economic growth is possible thanks to the departure from the assumptions of the neoclassical Cobb-Douglas production function, that assumes decreasing revenues from reproducible production factors. In the group of endogenous models there are at most constant revenues generated by these factors.

The practice of experience from recent decades refers to the statements formulated earlier in a severe form. There is always "something" that negates the assumptions of neoclassical as well as endogenous and the Mankiw-Romer-Weil models, which contradicts the transition from a non-competitive economy to a group of developed economies. (Johnson, 2017) Despite the absolute increase, this "gap" is not a stimulant reducing the distance, in spite of higher growth rate of weaker economies and due to the variability of the measurements that evaluate "modernity" (Aghda et al., 2018, Kostakis et al., 2018). In addition, "catching up" economies are intellectually "drained" by those developed, which, practically with only a few exceptions, such as raw material powers, does not allow these economies to achieve authentic convergence, outside their group. (Mankiw et al., 1992, Harari, 2017, 2018)

It should be noted that the above models are adapted to study the diminishing differences between developed economies that at their basis have the roots of early capitalist development. This refers for example to Poland, the Czech Republic, Slovenia, Slovakia, Hungary and other countries of the present EU that were stopped in their development of political processes caused by World War II. The situation is completely different in the group of countries totally exploited, such as postcolonial countries or those having expansive traditions dating back to the Latin and South American conquistador times. In the case of such powers as the USA exploration of the intellectual strength of Asian and European countries is also significant. (Horstmann et al., 2018) Already emphasized "brainwashing" and the research and development base typical of North America can not be discounted in the countries of Central and Eastern European countries with any outlays on this form of impact on the reduction of the distance. In convergence models, knowledge-based resources are a new dimension introduced into the Cobb-Douglas model. (King et al., 1988) The same occurs in multiplied form in the countries of Africa, Asia or South America. (Koellner et al., 2018)

For the study of convergence, i.e. to state the increase in the level of unification between social and economic differences in a sense, but not reduction of the distance, it is important to indicate, with the model, the occurrence of this phenomenon with indication of convergence coefficient or convergence to the long-term equilibrium. (Kraus \& Feuerriegel, 2017) 
Attention is drawn to the ascertainment, by the model, of the state of (long-term) dynamic inefficiency.

\section{Results and Discussion - Globalization processes in endogenous model format}

Starting from the assumption of the rationality of actions taken on the basis of scientific synthesis, it can be assumed that rapid civilizational progress that dramatically changes the cultural behaviour of humanity known to the present times is possible. Such a process is fulfilled, certainly with some limitations, and its origins date back to the Enlightenment period, from which the processes of social and economic development had to experience many regressions before they reached the current level. (Tavenner, 2018, Tobin \& Grand, 2004) The development of information technologies enhances civilization progress, while signaling at the same time unpredictable effects that can bring the entire civilization to total destruction. This is because the decisive significance of these technologies may dominate the reasonable and rational human decisions which, subordinated to algorithmically worked out solutions for emerging processes, may negatively affect the environment and lead to the tendency, not fully recognized yet, according to which masses of human beings would be subordinated to a small group of people ruling over them through algorithmic knowledge enhanced by the power of artificial intelligence and biotechnology. It is observed by many authors (Harari, 2017, Mellis et al., 2018), among others. In their works, they look at the past of the human species and assess their future while trying to outline the possible paths of change in the near future. According to their observations, first of all, it is necessary to change the political discourse that in many countries is currently focused on inappropriate issues. Such issues as nuclear war, climate change and innovative technologies are a priority for following the common sense while making local and current decisions that can only stimulate them.

The above-mentioned aspect of the threat of the fall of civilization has already been indicated not only in the scientological works. Processes of progress and global development have a tendency to turn back from the path of development and to change its trajectory in the opposite direction. (Wang Fenghui \& Hong-Kun, 2017, Wooldridge, 2002). At the same time, extremely negative phenomena that destroy the environment and threaten the destruction of civilization in the anticipatory vision of the future occur. (Klein, 2007). There is a difficult choice between social justice and economic efficiency. (Piketty, 2014)

\subsection{Convergence in the Face of Market Inefficiency - the Mankiw-Romer-Weil Methodology}

In the context of the above criticism, it would be important to determine the significance of the Solow model and its modifications, for verification of the thesis, whether they are useful in examining their compliance with the international variability of the standard of living. However, many studies referring to the construction of these models indicate that it is not always like this. The models are not always adequate to changing conditions or certain size variables in these models are inadequately measured. Most of the models created on the basis of the Solow model were supposed to examine the convergence of living standards, i.e. to determine whether poor countries grow faster than rich countries. Evidence shows that while maintaining population growth and capital accumulation at a stable level, countries are approaching a pace close to the level expected by the extended Solow model, i.e. the MankiwRomer-Weil model (M-R-W). The creation of this modified M-R-W model was to confirm 
that the neoclassical theory of growth explains well the differences in the level of income between countries and the phenomenon of conditional convergence. Therefore, many studies conducted in the following years present the results of conclusions that empirically verify the reliability of the Solow models (basic and extended) expressed in the Mankiw-Romer-Weil model $(\mathrm{M}-\mathrm{R}-\mathrm{W})$. Human capital $(\mathrm{H})$ is the third factor of production in the $(\mathrm{M}-\mathrm{R}-\mathrm{W})$ model, beside the physical capital $(\mathrm{K})$ and the effective labor resource $(\mathrm{A} \cdot \mathrm{L})$.

An important contribution to clarifying the abiguity and incompatibility appearing in various research results is brought by the de la Fuenta methodology. Based on the Mankiwa model, it introduces a significantly new standard resulting from the method of examining the Human Capital.

\subsection{The Essence of M-R-W's Model}

The creation of the modified M-R-W model (Mankiw at all (1992)) was also caused by the fact that the Solow model did not explain long-term balance in the study of convergence. Human capital $(\mathrm{H})$ appears in the M-R-W model for this purpose among others. Apart from physical capital $(\mathrm{K})$ and an effective labor resource $(\mathrm{A} \cdot \mathrm{L})$, human capital $(\mathrm{H})$ was introduced as previously mentioned as the third factor of production, directly to the Coobb-Douglas function. The properties of this function are particularly useful in explanation of growths. It also confirms some commonly used growth specifications, also known from other publications, that result from many studies on growth determinants with the assumption of an aggregated Cobb-Douglas production function, in the following form

$$
Y_{i t}=A_{i t} \cdot K_{i t}^{\alpha} \cdot L_{i t}^{\theta} \cdot H_{i t}^{\mu}
$$

where $A_{i t}$

$K_{i t} \quad$ represents physical capital resources,

$L_{i t}^{\theta} \quad$ represents employment level,

$H_{i t}^{\mu} \quad$ represents educational capital (average resources of human capital per

employee), and $i$ represents an object (country, region),

$A_{i t}$ coefficient summarizes the current state of technology and possibly omitted factors such as geographical location, climate, institutions and raw material resources.

The $\alpha, \theta, \mu$ coefficients measure the flexibility of performance in relation to the situation of a range of factors. For example, an increase of $1 \%$ of the resources of human capital of education per employee would increase production by $\mu \%$, while maintaining the status of other factors and the level of $A_{i t}$ of technical efficiency.

For the purposes of estimation, it is common to work with equation (2) after its logarithming and reformulation in terms of growth rate. The lowercase letters $\mathrm{y}, \mathrm{a}, \mathrm{k}, \mathrm{h}$ are applied for identification of logarithms of natural production quantities, capital, employment and educational capital and the combination of italics and lowercase letters and the symbol $" \Delta "$ for the determination of growth coefficients. (de la Fuente, 2003) This gives the following two specifications of the model (2):

$$
\begin{gathered}
y_{i t}=a_{i t}+k_{i t}^{\alpha}+l_{i t}^{\theta}+h_{i t}^{\mu}+\varepsilon_{i t} \\
\Delta y_{i t}=\Delta a_{i t}++\theta \cdot \alpha \cdot \Delta k_{i t}+\Delta l_{i t}+\mu \cdot \Delta h_{i t}+\Delta \varepsilon_{i t}
\end{gathered}
$$

where $\varepsilon_{i t}$ and $\Delta \varepsilon_{i t}$ are stochastic disturbances in the models (3) and (4). 
The equation which is not new in economic thought, obtained from the extended Solow model indicates that the factors determining the level of income are classical values: work $L$ and capital $K$ and other rates additionally introduced into the model, including the human capital factor $H$, in similarly developed form Jabłonski (2011). This did not change the features of production functions assumed in the neoclassical approach of Coob-Douglas, i.e. the decreasing marginal productivity of each factor, constant income from the scale, and the compliance with Inada's terms. The production goals also did not change and according to the developed form of the model it can be used in consumption, in the accumulation of physical capital or in the accumulation of human capital. The time concerning only the occurring technological changes that determine the value of production and the time dimension of its perception in a short or extended period is vital in the application of production function and in the process analysis. (Mankiw et al., 1992)

\subsection{Issues of Econometric Evaluation in Models of Socio-Economic Convergence}

The least problematic is the aspect of the study of the coherence diversity among the studied objects. It is accomplished by a simple method of examining $\sigma$ convergence in period $t(t=1,2, \ldots, T)$. The standard deviation of the natural logarithms of the product level is applied for mean values in period $t$ according to formula (1) where: $N$ represents the number of studied objects (regions) $i=1,2, \ldots, N$. We can speak about the occurrence of sigma convergence processes when the value of standard deviation $y_{i t}$ decreases from period to period.

On the other hand, endogenous models describing absolute convergence and conditional convergence have the form derived from logarithming from the equation (2).

In convergence studies, the nature of the variables which is hard to determine, and the way in which they are connected constitute the problem that is often encountered. (de la Fuente, 2000). For many factors of growth, the theory does not explicitly determine whether a given variable has endogenous or exogenous character. In econometric studies, the variable $x_{i}$ is endogenous whereas $E\left(x_{i t}, \xi_{i s}\right) \neq 0$ for all $\mathrm{t}, \mathrm{s}=1,2, \ldots$, T. However, if $E\left(x_{i t}, \xi_{i s}\right)=0$ for all $\mathrm{t}, \mathrm{s}=1,2, \ldots, \mathrm{T}$, then the variable is strictly exogenous. Endogeneity may occur when we deal (Wooldridge J.M., (2002)) with omitted variables that should be included in the model, but due to their inaccessibility or large errors in their measurement are not introduced into the model. In such a situation, studies should be performed with the use of panel data, since the introduction of such a variable would be detrimental to the properties of the random component which "absorbs" the related errors of the lack of variable or imperfect observation of the introduced variable, just like in the case of explaining the variable $x_{i}$ by the variable $y$ and vice versa (simultaneity).

The face of convergence becomes a challenge for research and methods, which is the result of estimating the GDP of individual economies in the analysed period. The results of literature studies presented here relate to the model measurement of real convergence on the basis of research with the use of the Mankiw model (1992), in terms of variables considering the knowledge capital.

In the model of $\beta$ type conditional convergence, regression is an extended Solow model with physical and human capital included, as well as the time effect. From numerous studies known from the literature (Islam, 2003) and from what is confirmed by the results obtained here, it can be concluded that small groups of countries develop according to the convergence hypothesis, as proved by both absolute and conditional convergence type. It has already been mentioned many problems of numerical nature and those referring to the estimation of knowledge capital (the scholarisation factor) arise in the estimation of the degree of 
convergence. Data panels are used for the convergence analysis then. Many researchers work in this way and apply data concerning regions of the NUTS-2 level of the European Union countries. The use of panel data together with appropriate estimation techniques enables the resolution of many of the above-mentioned problems. Today, panel models are the basic tool for empirical verification of the theory of growth. Pooled model, fixed effects model (LSDV Squares Dummy Variable Model), as well as a dynamic model estimated with the use of the UMM System Estimator are applied. (Wędrowska, 2013)

In research de la Fuente (2003), he pays special attention to econometric problems resulting from the introduction of the method of measuring the knowledge factor as capital in the Mankiw model. He also ascertains some commonly used growth specification that result from many studies on growth determinants at the assumption of an aggregated Cobb-Douglas production function in (2) form, that are also known from other publications.

One of the difficulties that arises at this moment is that both equations (3) and (4) contain variable quantities that are not directly observable (in particular the natural logarithm $a_{i t}$ of the TFP level, and its growth rate, $\Delta a_{i t}$ ). To continue the estimation, further assumptions about the behaviour of these quantities should be made. Different assumptions will generate different econometric specifications. The simplest option is to assume that the pace of technological progress is constant over time and between countries, i.e

$$
\Delta a_{i t}=\mathrm{g}
$$

for all $i$ elements and $t$ elements. In this case, $g$ can be estimated as the regression constant in the equation (3), and $a_{i t}$ is replaced in the equation (2) by $a_{i t}+g \cdot t$, where $a_{i t}$ results in the formation of specific constants for a given $i$ country and a common trend.

Determination of $a_{i t}$ in the equation (3) as a function of other variables is an alternative and more sophisticated approach. The relatively general specification of this technological progress function (reflecting those applied in the studies analysed in the supplement to the report. (de la Fuente, 2003) and considering the impact on the rate of human capital is given as the following:

$$
\Delta a_{i t}=\gamma_{i 0}+\gamma_{b} \cdot b_{i t}+{ }_{h} H_{i t}+{ }_{\gamma_{b \cdot h}} H_{i t} \cdot b_{i t}+{ }_{\gamma \cdot r} R D_{i t}
$$

where $H$ is the average state of human capital, RD is a measure of $\mathrm{R} \& \mathrm{D}$ expenditures; it is a circumvention of a technological gap between the country $i$ and the best global economy.

When data about the factor stocks or their growth rates are not available (or are not considered reliable), the observed investment rates can be used to construct the approximation of variables introduced into equations (2) and (3). These approximations are usually obtained with the use of the generalized Mankiw model. In such a model, long-term values of balance factor coefficients are simple functions of investment rates, and maintenance of these indicators far from such an equilibrium can be approximated as a function of investment rates and initial income per employee. If we want to assume that most countries are reasonably close to their long-term equilibrium, equation (2) can be replaced by the equation regarding the ratio of production per employee to the rates of investments in physical and human capital. Otherwise, the equation will also include output data per worker as an additional regressor to capture temporary dynamics along the adjustment to long-term equilibrium. Two, rather standard, specifications of the resultant equilibrium and convergence equations are obtained, which, however, do not allow to determine the effects of frequency. (de la Fuente, 2003) There are investments in physical and human capital measured as a fraction of GDP, the rate of growth in employment or labour resources and the depreciation rate (which is equal for both types of capital). In addition, there is a $\beta$ parameter measuring the speed of approaching to long-term equilibrium and it can be shown here that this is a function of the 
degree of return to scale in both types of capital considered together and the length of the period in which observations are performed.

Until now, it has been assumed that human capital resources per employee, $H$, are directly observable. In practice, however, average years of learning, $Y \cdot S$ are usually observed, and estimation of the empirical model requires some assumption as to the form of function regarding these two variables, $H=g(Y \cdot S)$. The use of this function in equation (2), determines the production of a simplified function related to the change of $Y$ to $Y \cdot S$. To avoid misunderstandings, we will refer to the flexibility of this production function of reduced form with respect to school years as $\alpha \cdot Y \cdot S$ (it should be noted that this parameter will generally differ from $\alpha \cdot h$ ). Similarly, when $Y$ replaces $H$ in the function of technological progress (5), the $\gamma \cdot Y S$ designation for the parameters of the rate of effects will be used. It measures the contribution of an additional year of school in TFP growth rate. It is quite common in the literature to assume about the nature $\mathrm{g}(\cdot)$ that $H=Y \cdot S$. In this case, all of the above equations remain valid, and $\mathrm{H}$ is replaced by $Y \cdot S$, and ah is replaced by $\alpha \cdot Y \cdot S$. Secondly, the following can be assumed here

$$
\mathrm{H}=\exp (\theta \cdot Y \cdot S)
$$

It is often called the Mincer specification, because it is compatible with the functional form commonly used in microeconomic pay equations. (Mincer \& Polachek, 1974) In this case the exponential equation (6) reverses the logarithm in the Cobb-Douglas function and the equations above must be changed accordingly. In in particular, $\mathrm{H}$ values should be replaced with $Y \cdot S$ levels and growth rates $\mathrm{H}$ by mean YS variations. It should be noted that if the expression in the equation (6) is considered in the Cobb-Douglas function given in equation (2), the $Y \cdot S$ factor in the obtained equation,

$$
\rho=\alpha_{h} \cdot \theta,
$$

measures the percentage increase in production, which results from the increase in the average school period by one year. The $\rho$ value is an aggregate or macroeconomically defining the value of the assessment of a return to learning. As explained in the literature, this variable must be distinguished from the "proper" rate of return to learning, which is defined and calculated in literature. (de la Fuente, 2003)

As it has already been mentioned, measurement error is always a problem in the review literature because the years of the school variable used in most empirical applications are certainly an imperfect measure of human capital. Therefore, many estimated models show a low level of explanation of the status of dependent variable by the used variables the convergence models. It can be added that poor data quality can be an important problem because most of the existing sets of data concerning education in international dimension seem to contain a significant amount of noise resulting from various inconsistencies in the primary data used to create them. Noise, which is generally expected, will bring a downward deviation of the estimated human capital coefficients (i.e. a tendency to underestimate their value), because it generates an apparent changeability of the measured human capital resource, which will not be compared with changes in the performance.

\subsection{Selected Results of the Convergence Estimation}

Numerous estimates of endogenous models derived from the modification of the Solow model show that convergence is frequent. However, the estimated models are also often characterized by low explanatory power measured by the coefficient of determination. Nevertheless, references to the procedures of convergence analysis by many authors are 
important. They differently assess the usefulness of model results. The arguments given above that refer to the study of the indicator assessing the impact of human capital measured by various scholarisation indicators can radically change the obtained convergence assessment. The results explicitly depend on the method of the model estimation, i.e. whether it is done on the basis of panel or cross-sectional data. The following reliable matched results were obtained in selected models estimated by A. Fuente i N.Islam:

1. Investigating the convergence of 19 OECD countries in the period 1965-1995 (de la Fuente, 2003), i.e. for an increased period and the number of countries expanded by one country, he stated that there was a conditional convergence at: $\beta=-0,034$ and adjustment of the $R^{2}=0,78$. model. This regression was examined on the basis of the Solow model with physical, human and technological capital as well as trend, technological gap, professional activity, unemployment and state expenditure variables.

2. Investigating the convergence of 18 OECD countries in the period 1970-1995 (de la Fuente, 2003), stated absolute convergence on the basis of the value of the determined convergence parameter: $\beta=-0.16$. The negative value of this parameter determining the convergence rate proves that the parameter $\theta=-\left[\frac{(1-\exp (-\beta \cdot T))}{T}\right]$ appearing in the convergence model with the initial level of capital $y_{i o}$, where $i$ represents the country number, is always negative, which means that the deviation of the regression line is slightly declining. However, the value $R^{2}=0,52$ of the absolute convergence was not very high.

3. Explicitly well-estimated models were obtained also by Islam (1995), who investigated the conditional $\beta$ convergence of groups of different countries in the years 1960-1985. He recognised conditional convergence, i.e. convergence of less developed and more developed countries to the state of long-term equilibrium in each of the models studied on the basis of panel data. In these models, on the basis of estimated model, and at $R^{2}=0,75$ he stated the occurrence of $\beta$-convergence, $\beta=4.34 \%$ and $5.07 \%$ for a group of 96 countries. He included in this model only physical capital (without human capital) based on panel data. It was therefore a typical neo-classical Solow model. In contrast, for the group of 79 countries on the basis of panel data including human capital, i.e. the "school" variable, he stated the same convergence $\beta,(\beta=3,75 \%)$.

4. In the Solow model for the group of 22 OECD countries, N. Islam stated the conditional convergence $\beta,(\beta=6,70 \%$ oraz $10,75 \%)$ on the basis of explanatory models with $R^{2}=$ 0,96 oraz 0,97 , respectively (Islam (1995)). Using the panel data and the model with human and physical capital, he found conditional convergence $\beta$ with the value of $9.13 \%$ (he does not provide here the explanatory power of the model).

The main conclusions found in the literature on convergence models overlap with already formulated objections. In general, the world as a whole does not develop in accordance with the hypothesis of the absolute convergence of the $\beta$ type. Countries less developed in the average sense do not show faster growth than developed countries. This is confirmed by extensive research performed on diverse groups of countries. (Mankiw et al., 1992) mainly due to the reasons that we have paid attention to in the paper. Nevertheless, in the groups of relatively homogenous countries, the phenomenon of convergence can be confirmed.

\section{Conclusion}

The main results regarding the objectives of the paper are related to the analysis of similarities in terms of convergence processes in the countries, including physical and human capital, and labour resources. References concerning the main objective of the considerations 
may lead to the conclusion that the phenomenon of convergence raises some methodological controversies resulting from the approach to the very method of estimation of GDP per capita, but mainly from an additional scholarisation variable. Various sources, often diverging in the estimation of specific economic indicators, prove that the contribution of human capital in countries with a strong underdevelopment was following what was not always positive in other regions of the world. Studies on the convergence of EU countries are widely commented in the literature. For this reason, too little attention has been devoted to this subject. It can only be stated with a high degree of probability that as a result of transformation processes Central and Eastern European countries gained the most in the context of convergence processes in other parts of the world.

In the context of presented results of De la Fuente's research on the analysed convergence of groups of countries, regions of the world that need special attention due to their overall neglect and, at the same time, huge opportunities for potential development are presented in the model. In terms of the methodology used in the article, the attention was focused on the model very close to the Solow model. This is a justified approach, but due to the problems with the estimation of such models, special attention has been paid to De la Fuente's research (2003).

\section{References}

Aghda, A.S.F., Hosseini, S.M. \& Tahmasebi, M. (2018). Convergence and Non-Negativity Preserving of the Solution of Balanced Method for the Delay CIR Model with Jump. Journal of Computational and Applied Mathematics, 344, 676-690.

Bal-Domanska, B. (2013). Procesy Konwergencji Wydajności Pracy w Regionach Unii Europejskiej. Wiadomości Statystyczne, 2(621), 2-3.

Barro, R.J. \& Sala-i-Martin, X. (1990). A Spatial Mankiw-Romer-Weil Model: Theory and Evidence. The Annals of Regional Science, 47(2), 419-436.

Barro, R.J. \& Sala-i-Martin, X. (1995). Economic Growth. McGraw-Hill, 539.

Dowrick, S. \& Rogers, M. (2002). Classical and Technological Convergence: Beyond the Solow-Swan Growth Model. Oxford Economic Papers, 54(3), 369-385.

Fridmann, J. (2011). Insurgencies: Essays in Planning Theory. Abingdon: Routledge.

de la Fuente, A. \& Domenech, R. (2000). Human Capital in Growth Regressions: How Much Difference Does Data Quality Make? Mimeo, Instituto de Análisis Económico.

de la Fuente A. (2003). Human Capital in a Global and Knowledge-Based Economy, Part II: Assessment at the EU Country Level. Working Papers 98. Barcelona Graduate School of Economics.

Gariepy, F. (2018). The moral Realism and the Convergence of Beliefs. Phares-Revue Philosophique Etudiante del Universite, 18, 171-192.

Halkos, G.E. \& Tsionas, G.E. (2001). Environmental Kuznets Curves: Bayesian Evidence from Switching Regime Models. Energy Economics, 23(2), 191-210.

Harrari, Y.N. (2017). Homo Deus, Wydawca: Vintage Publishing.

Horstmann, G.M., Schiepel, D. \& Wagner, C. (2018). Experimental Study of the Global Flow-State Transformation in a Rectangular Rayleigh-Benard Sample. International Journal of Heat and Mass Transfer, 126, 1333-1346.

Islam, N. (1995). Growth Empirics: A Panel Data Approach. Quarterly Journal of Economics, 110, 1127-1170.

Islam, N. (2003). What Have We Learnt from the Convergence Debate? Journal of Economics Surveys, 17, 309362.

Jabłonski, Ł. (2011). Human Capital in Selected models of Economic Growth.m Gospodarka Narodowa, 1-2, 81-103.

Johnson, S. (2017). Competing Visions of Financial Inclusion in Kenya: The Rift Revealed by Mobile Money Transfer. Canadian Journal of Development Studies-Revue Canadienne d Etudes du Developpement, 38(2), 296-296.

King, R.G., Plosser, Ch.I. \& Rebelo, S.T. (1988). Production, Growth and Business Cycles: I. the Basic Neoclassical Model. Journal of Monetary Economics, 21(2-3), 195-238.

Klein, N. (2007). The Shock Doctrine: The Rise of Disaster Capitalism. New York, US. 
Kostakis, V., Latoufis, K., Liarokapis, M. et al. (2018). The convergence of Digital Commons with Local Manufacturing from a Degrowth Perspective: Two Illustrative Cases. Journal of Cleaner Production, 197, 1684-1693.

Koellner, T., Schroeter, M., Schulp, C.J.E. et al. (2018). Global Flows of Ecosystem Services Ecosystem Services, 31, 229-230.

Kraus, M. \& Feuerriegel, S. (2017). Decision Support from Financial Disclosures with Deep Neural Networks and Transfer Learning. Decision Support Systems, 104, 38-48.

Mankiw, N., Romer \& Weil, N.D. (1992). A Contribution to the Empirics of Economic Growth. Quarterly Journal of Economics, 107, 407 - 437.

Mellis, A.M., Athamneh, L.N., Stein, J.S. et al. (2018). Less Is More: Negative Income Shock Increases Immediate Preference In Cross Commodity Discounting and Food Demand. Appetite, 129, 155-161.

Mincer, J. \& Polachek S. (1974). Family Investment in Human Capital: Earnings of Woman. Journal of Political Economy, 82(2), 76-108.

Paltan, H., Haustein, K. et al. (2018). Global Implications of 1.5 Degrees C and 2 Degrees C Warmer Worlds on Extreme River Flows. Environmental Research Letters, 13(9).

Piketty, T. (2014). Capital in the Twenty-First Century. London, England: The Belknap Press of Harvard University Press.

Reisman, G. (2015). Capitalism: A Treatise on Economics. Publisher: Fijorr Publishing.

Rifkin, J. (2000). The Age of Access: The New Culture of Hipercapitalism, Where all of life is a Paid-For Experience. New York: Tarcher.

Rodrik, D. (2011). Paper prepared for 2011 The Jackson Hole Symposium of the Federal Reserve Bank in Kansas City. Cambridge, US, 25-27.

Romer, P.M. (1986). Increasing Returns and Long-Run Growth. The Journal of Political Economy, 94, 5, $1002-$ 1037.

Samuelson, P. \& Nordhaus, W. (2010). Economics. Nineteenth Edition. The McGraw-Hill Companies, Inc.

Solow, R.M. (1956). A Contribution to the Theory of Economic Growth. The Quarterly Journal of Economics, 70(1), 65-94.

Solow, R.M. (1980). The Story of a Social Experiment and Some reflections. (Geary Lecture), Dublin: Economic and Social Research Institute.

Tavenner, K. \& Crane, T.A. (2018). Gender Power in Kenyan Dairy: Cows, Commodities, and Commercialization. Agriculture and Human Values, 35(3), 701-715.

Tobin Grand, J. \& Rudolph, T.J. (2004). Expression vs. Equality. The Politics of Campaign Finance Reform. The Ohio State University Press - Columbus.

Tokarski, T. (2007). Efekty Skali a Wzrost Gospodarczy. Gospodarka Narodowa, 1-2, 9-31.

Van Ewijk, S.J.A. \& Ekins, P. (2018). Global Life Cycle Paper Flows, Recycling Metrics, and Material Efficiency. Journal of Industrial Ecology, 22(4), 686-693.

Wang, F. \& Xu, H-K. (2017). Weak and Strong Convergence of Two Algorithms for the Split Fixed Point Problem. Proceedings of the Workshop on Computational Mathematics and Scientific Computing. Macau, China.

Wędrowska, E. (2013). Konwergencja Gospodarcza w Województwach Polski w Latach 2000-2012. Roczniki Kolegium Analiz Ekonomicznych/Szkoła Gtówna Handlowa, 36, 403-412.

Wooldridge, J.M. (2002). Introductory Econometrics. A modern approach, $5^{\text {th }}$ edition. Michigan State University, South-Westend. 